\title{
可见光促进的组氨酸碳氢键烷基化反应
}

\author{
占贝贝史炳锋* \\ (浙江大学化学系 杭州 310027)
}

\section{Visible-Light-Promoted Histidine-Specific Peptide C-H Alkylation}

\author{
Zhan, Beibei Shi, Bingfeng* \\ (Department of Chemistry, Zhejiang University, Hangzhou 310027)
}

多肽是一类非常重要的生物分子, 作为蛋白质的基 本单元和候选药物, 已在生物化学和制药领域引起了广 泛关注 ${ }^{[1]}$. 与自然界存在的多肽相比, 非天然肽在某些 方面显示出更好的生物活性和药代动力学特性 ${ }^{[2]}$. 通过 化学修饰的方法在多肽的氨基酸残基上进行位置选择 性地修饰，可以简化合成步骤，从而更加高效合成具有 生物活性的多肽类似物. 然而现有多肽的修饰方法主要 局限于半胱氨酸 ${ }^{[3]}$ 和赖氨酸 ${ }^{[4]}$ 等亲核性基团, 突破该类 反应的局限性, 将极大地扩展多肽选择性官能团化的方 法. 组氨酸带有独特的咪唑侧链, 在多肽和蛋白质中起 着不可替代的作用. 目前组氨酸的位置选择性修饰策略 主要依赖于咪唑基团弱亲核性进行 $\mathrm{N}$ 取代反应, 但是该 反应常受到半胱氨颈基和赖氨酸氨基的干扰. 因此如何 在更为广泛的反应类型或底物上对组氨酸进行修饰, 仍 是该领域研究的巨大挑战.

近年来, 碳氢键的直接官能团化为多肽的修饰提供 了一种全新的策略 ${ }^{[5]}$. 然而多肽后期碳氢键的直接官能 团化与各类官能团的兼容性在一定程度上限制了该领
域的进一步发展，除了来自亲核基团的干扰之外，还要 避免半胱氨酸、蛋氨酸、组氨酸和酪氨酸的氧化. 组氨 酸(His)带有独特的缺电子咪唑侧链, 可以在生理条件下 使咪唑的氮原子质子化, 以使咪唑环的 $\mathrm{C}(2)$ 位置在肽侧 链和主链上具有独特的缺电性. 上海交通大学化学化工 学院王平课题组和南开大学化学学院陈弓课题组认为, 可以通过 Minisci 型自由基介导的碳氢键烷基化反应结 合咪唑环的缺电性, 对组氨酸进行化学选择性修饰.

近日，该研究团队利用汉斯酯类化合物(DHP-R)作 为烷基自由基前体，在可见光的促进下实现了对复杂多 肽序列中组氨酸咪唑环的 C(2)位烷基化反应，从而构建 了一系列重要的多肽药物库 ${ }^{[6]}$.

该方法反应条件温和，化学选择性高，对不同的汉 斯酯都有很好的兼容性. 值得一提的是，该方法能够对 血管紧张素 II (Angiotensin II)、亮丙瑞林(Leuprorelin)、 戈那瑞林(Gonadorelin)甚至含有更长肽链的促皮质素 (Cosyntropin)、肠促胰液素(Secretin)、艾塞那肽 (Exenatide)、利西拉肽(Lixisenatide)和泛激素(Ubiquitin)

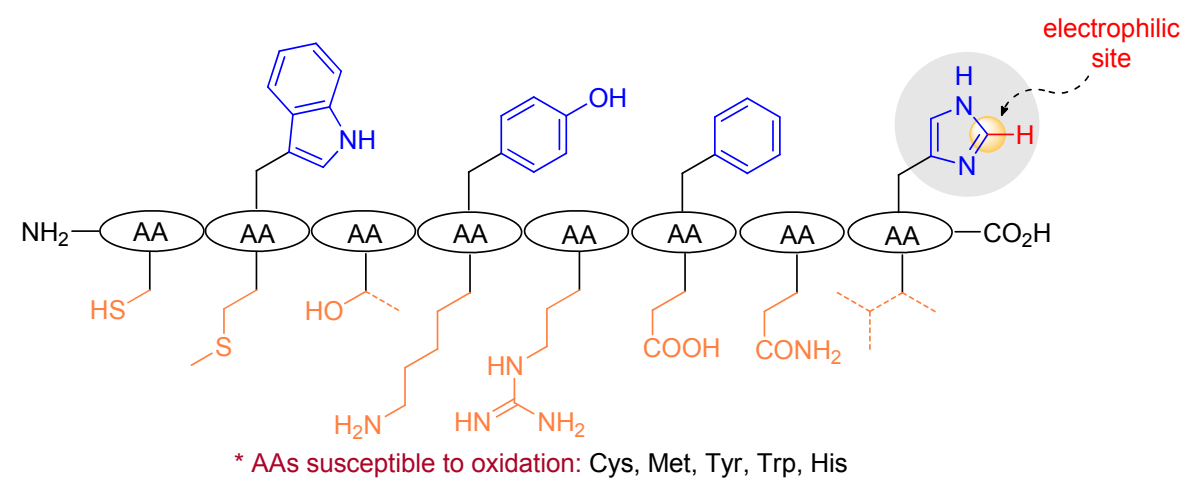

图 1 多肽和蛋白质中常见的氨基酸残基

Figure 1 Representative proteinogenic amino acid residues of peptides and proteins

* Corresponding author. E-mail: bfshi@zju.edu.cn. published online December 18, 2019. 


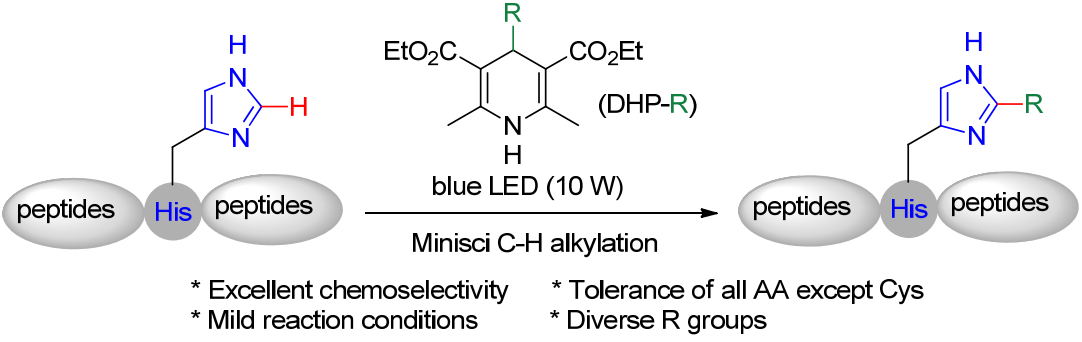

图 2 可见光促进组氨酸咪唑环 $\mathrm{C}(2)$ 位的烷基化反应

Figure 2 Visible-light-promoted $\mathrm{C}(2) \mathrm{C}-\mathrm{H}$ alkylation of histidine

等多肽类药物进行后期修饰. 为了进一步体现该方法的 应用价值, 研究人员还尝试将该反应应用到复杂非天然 多肽药物的后期衍生化中. 布美诺泰(Bremelanotide, 用 于治疗女性性功能障碍的环状肽) 与汉斯酯反应, 能以 较好的收率得到相应的烷基化产物 1-a. 博来霉素 (Bleomycin A2) 是一种广谱糖肽抗生素及抗肿瘤药物, 其结构包含许多潜在的干扰基团，例如联噻唑、嘧啶、 硫正离子和对酸敏感的二糖部分. 合成化学家 Boger ${ }^{[7]}$ 与 $\mathrm{Hecht}^{\left[{ }^{8]}\right.}$ 曾经对其进行化学合成以及结构改造, 需要 几十步线性路线. 研究团队发现博来霉素与金刚烷基自 由基前体反应几乎能够以定量的收率得到产物 2-g, 从 而实现对其组氨酸的高效修饰.

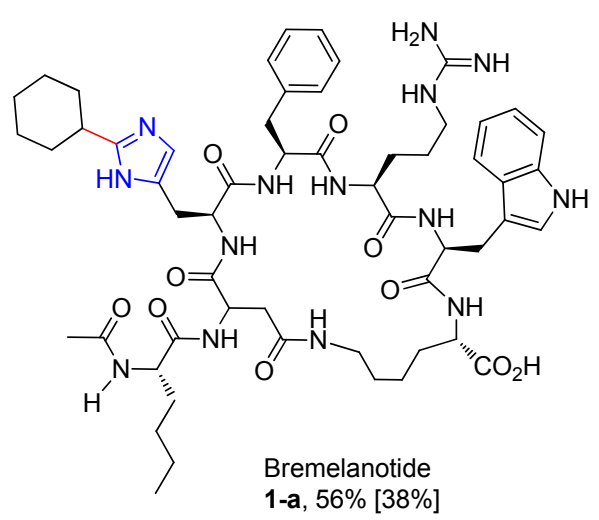

机理研究表明，该反应很可能遵循缺电子杂芳基自由基介导的 Minisci 型碳氢键官能化的机理. 反应通 过亲核烷基自由基进攻咪唑的缺电 $\mathrm{C}(2)$ 位置, 然后经过 氢转移 (HAT) 或单电子转移/质子转移 $\left(\mathrm{SET} / \mathrm{H}^{+}\right)$, 在 DHP-R 的氧化作用下脱氢芳构化得到目标产物. 反应 体系中的汉斯酯同时起到自由基前体以及温和氧化剂 的双重作用. 王平和陈弓团队基于经典的 Minisci 反应, 发展了对多肽或蛋白质序列中组氨酸咪唑环的 $\mathrm{C}(2)$ 位 高选择性烷基化反应. 该方法成功实现了对多肽或蛋白 质的修饰和改性, 并且有望在药物化学研究和生物标记 等领域发挥重要作用.

图 3 可见光促进复杂多肽药物的后期修饰

Figure 3 Visible-light-promoted late stage modification of complex peptides Isolated yields were provided in square brackets

\section{References}

[1] Albericio, F.; Kruger, H. G. Future Med. Chem. 2012, 4, 1527.

[2] Rémond, E.; Martin, C.; Martinez, J.; Cavelier, F. Chem. Rev. 2016, 116, 11654.

[3] Zhang, C.; Vinogradova, E. V.; Spokoyny, A. M.; Buchwald, S. L.; Pentelute, B. L. Angew. Chem., Int. Ed. 2019, 58, 4810.

[4] Amamoto, Y.; Aoi, Y.; Nagashima, N.; Suto, H.; Yoshidome, D.; Arimura, Y.; Osakabe, A.; Kato, D.; Kurumizaka, H.; Kawashima, S. A.; Yamatsugu, K.; Kanai, M. J. Am. Chem. Soc. 2017, 139,
7568 .

[5] Wang, W.; Lorion, M.; Shah, J.; Kapdi, A. R.; Ackermann, L. Angew. Chem., Int. Ed. 2018, 57, 14700.

[6] Chen, X. P.; Ye, F. R.; Luo, X. S.; Liu, X. Y.; Zhao, J.; Wang, S. Y. Zhou, Q. Q.; Chen, G.; Wang, P. J. Am. Chem. Soc. 2019, 141, 18230 .

[7] Boger, D. L.; Honda, T.; Menezes, R. F.; Colletti, S. L. J. Am. Chem. Soc. 1994, 116, 5631.

[8] Hecht, S. M. Acc. Chem. Res. 1986, 19, 383.

(Cheng, F.) 